\title{
A comparison of CFRP composite laminated joints fabricated with vacuum assisted resin transfer molding
}

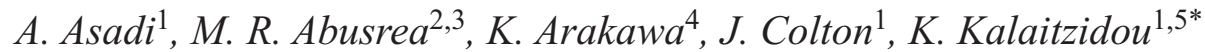 \\ ${ }^{1}$ G. W. Woodruff School of Mechanical Engineering, Georgia Institute of Technology, GA 30332 Atlanta, USA \\ ${ }^{2}$ Interdisciplinary Graduate School of Engineering, Sciences, Kyushu University, 816-8085 Fukuoka, Japan \\ ${ }^{3}$ Faculty of Engineering, Cairo University, 12613 Giza, Egypt \\ ${ }^{4}$ Research Institute for Applied Mechanics, Kyushu University, 8168580 Fukuoka, Japan \\ ${ }^{5}$ School of Materials Science and Engineering - Georgia Institute of Technology, GA 30332 Atlanta, USA
}

Received 16 January 2018; accepted in revised form 7 April 2018

\begin{abstract}
The objective of this study is to improve the mechanical performance of carbon fiber reinforced polymer (CFRP) adhesive joints, called 'laminated joints'. The laminated joints are made by stacking two dry carbon fiber fabric halves together and molding using vacuum-assisted resin transfer molding (VARTM) process. An improved design of this joint was fabricated by overlapping the two half fabrics and adding extra carbon fiber fabric pieces. Four joints are considered in this work: a conventional laminated joint, two laminated joints with overlap, and a multiple-covers laminated joint. The composite joints are characterized in terms of static flexural and impact strength and fatigue performance. In addition, post-fracture analysis is performed using optical microscopy to identify the dependence of failure modes and its propagation in composite joints.
\end{abstract}

Keywords: polymer composites, CFRP adhesive laminated joint, mechanical properties

\section{Introduction}

Structural applications of composite materials are increasing due to their excellent mechanical properties, specifically high stiffness-to-weight and strength-toweight ratios. Carbon fiber reinforced polymer (CFRP) composites are among the best in terms of performance mainly due to the unique properties of carbon fibers (CF). CFRP composites can be processed by a variety of methods but the most appealing ones are out-of-autoclave processes that can ensure high quality products at minimum cost and high production rates such as vacuum assisted resin transfer molding (VARTM). CFRP composites are used in various applications including offshore wind turbines, bridges, buildings, other large civil engineering structures, ships and aerospace [1-6]. Due to their size, it is not practical to fabricate or transport these as complete structures. As a result, they are manufactured as smaller components and joined together. There are many ways to attach composite components together, such as mechanical fastening [7, 8], welding [9], co-curing [10], and adhesive bonding [11]. Adhesive bonding is widely used [12] due to its advantages compared to mechanically fastened joints, such as low stress concentrations, more uniform load distribution, small weight penalty, and better fatigue behaviour $[13,14]$. These structures are subjected to combinations of mechanical loadings, including static, fatigue and impact loadings and thus the mechanical performance of these structures is highly dependent on the joining efficiency.

This paper focuses on improvement of mechanical performance of CFRP adhesive joints, called 'laminated joints'. Examples of CFRP composite adhesive joints include single-lap [15, 16], double-lap $[17,18]$, stepped [19, 20], and scarf-lap [21-24]. Two novel

"Corresponding author, e-mail: kyriaki.kalaitzidou@me.gatech.edu (C) BME-PT 
modifications were made to create the laminated joints. The first involved overlapping the two halves with overlap lengths of 20 and $40 \mathrm{~mm}$. The second involved the addition of carbon fiber pieces to create a multiple-covers laminated joint, MCL. The CFRP joints and fabrics were made using VARTM and compared to one another in terms of flexural properties in both static and fatigue loadings, and impact strength. In addition, the fracture surfaces generated during impact testing are investigated using microscopy in order to identify possible differences in the failure mode as a function of the type of joint. Finally, the void content and density of the various jointed composites are also determined and considered in the discussion of what joints are more efficient as the weight of a joint is a very critical factor. For example, an application where the joints should not add any weight to the structure is in wind turbine blades for power generation. However, it is noted that the joints developed and tested in this study are appropriate to bond any CFRP components.

\section{Experimental details}

\subsection{Materials}

The materials used are carbon fabrics and an epoxy resin available as Denatite XNR6815/XNH6815 [25]. The following three different types of carbon fibers were used. All of them were Mitsubishi Rayon and with the characteristics of each one as follows: Type 1 is UD $1 \mathrm{M} ; 317 \mathrm{~g} / \mathrm{m}^{2}$; type 2 is UD $1 \mathrm{M} ; 212 \mathrm{~g} / \mathrm{m}^{2}$ and type 3 is plain, $60 \mathrm{~g} / \mathrm{m}^{2}$ as shown in Table 1. Carbon fiber type 1 is used in the majority of the study and carbon fibers of types 2 and 3 only as extra fabric pieces in case of the multiple-covers laminated joint as presented in Figure 1.

\subsection{Fabrication of adhesive joints}

Four types of joints were fabricated using the VARTM method and compared in terms of their mechanical properties to jointless CFRP composites. The four types are i) laminated joint, ii) laminated joint with an overlap of $20 \mathrm{~mm}$, iii) laminated joint with an overlap of $40 \mathrm{~mm}$ and iv) joint with multiple-covers.

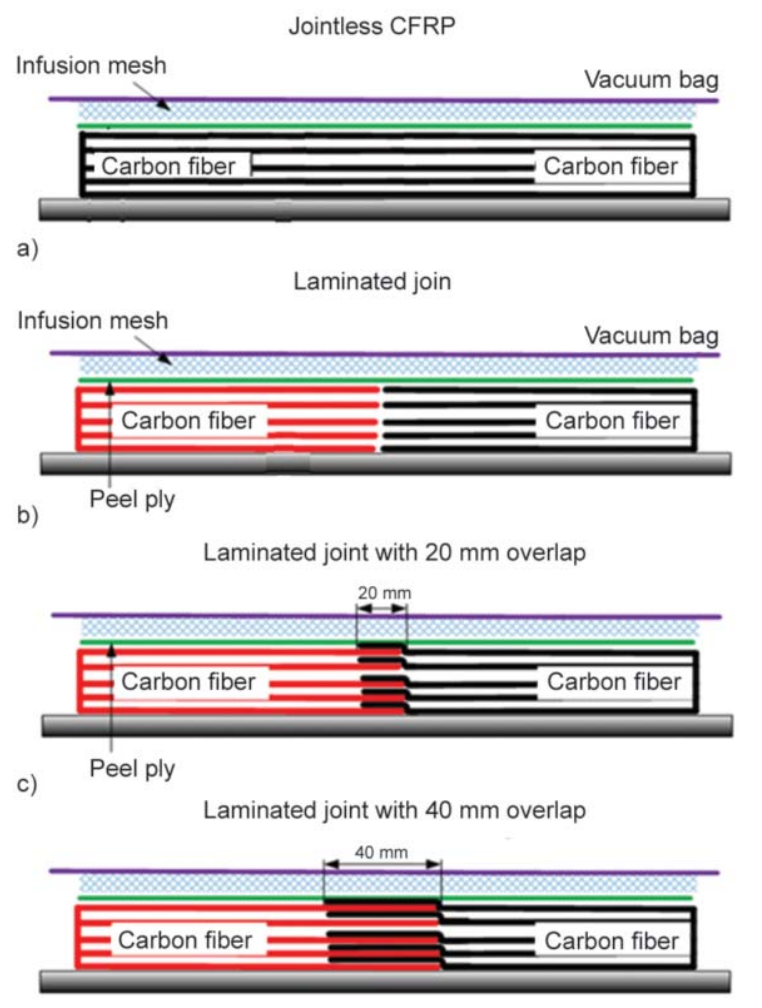

d) Multiple-covers laminated join

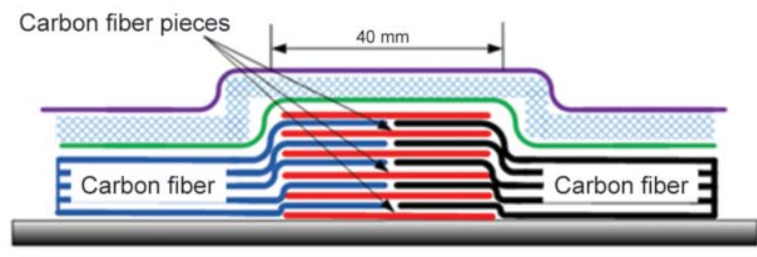

e)

Figure 1. (a) Jointless CFRP, (b) Laminated joint, (c) Laminated joint with $20 \mathrm{~mm}$ overlap, (d) Laminated joint with $40 \mathrm{~mm}$ overlap, (e) Multiple-covers laminated joint.

The type of joint proposed in this work is a laminated adhesive joint that consists of two 6-layer drycarbon half fabrics stacked together in mating formation. The improvement in this type of joint comes from the fact that the two halves overlap. To highlight the effect of the length of the overlap, two different joints with an overlap length of 20 and $40 \mathrm{~mm}$ were investigated. Another improvement is due to the addition of $40 \mathrm{~mm}$ long extra pieces of carbon fiber fabric that were inserted between the carbon

Table 1. Characteristics of the carbon fibre types used in this work.

\begin{tabular}{|c|l|l|c|c|c|c|c|c|}
\hline Type & $\begin{array}{c}\text { Carbon fiber } \\
\text { designation }\end{array}$ & Style & $\begin{array}{c}\text { Weight } \\
{\left[\mathbf{g} / \mathbf{m}^{\mathbf{2}}\right]}\end{array}$ & $\begin{array}{c}\text { Density } \\
{\left[\mathbf{g} / \mathbf{c m}^{\mathbf{3}}\right]}\end{array}$ & $\begin{array}{c}\text { Thickness } \\
{[\mathbf{m m}]}\end{array}$ & $\begin{array}{c}\text { Tensile strength } \\
{[\mathbf{M P G}]}\end{array}$ & $\begin{array}{c}\text { Tensile modulus } \\
{[\mathbf{G P a}]}\end{array}$ & $\begin{array}{c}\text { Elongation } \\
{[\mathbf{\%}]}\end{array}$ \\
\hline 1 & TRK976PQRW & UD & 317 & 1.82 & 0.33 & 4900 & 253 & 1.9 \\
\hline 2 & TRK979PQRW & UD & 212 & 1.82 & 0.25 & 4900 & 253 & 1.9 \\
\hline 3 & TR30S3L & Plain & 60 & 1.79 & 0.09 & 4410 & 234 & 1.9 \\
\hline
\end{tabular}




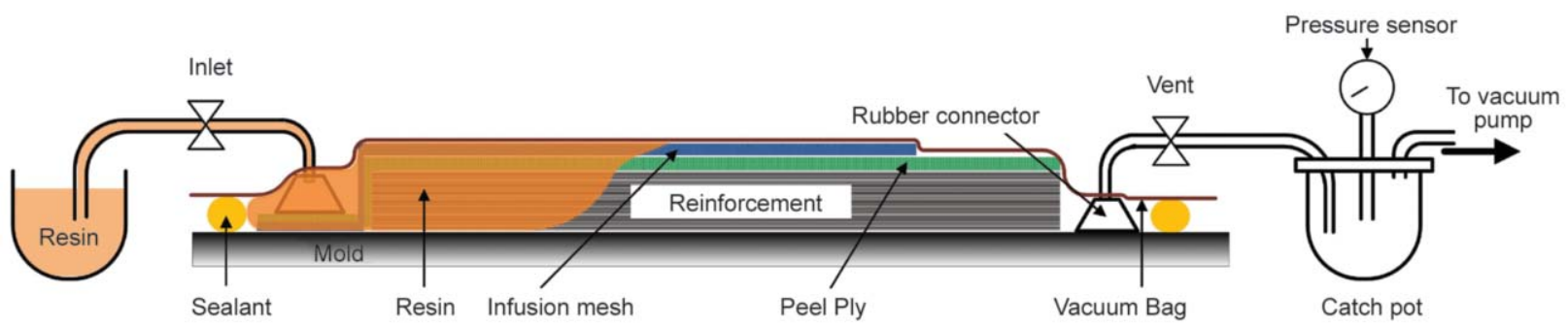

Figure 2. Schematic representation of the VARTM process.

fiber layers to enhance the contact between the two joint halves. In this type of joint the bottom carbon fiber piece is made from type 2 fibers whereas the rest of the pieces from type 3 carbon fibers (see Table 1).

A schematic description of the VARTM method used to fabricate the joints is shown in Figure 2. First the carbon fiber fabrics were placed on the mold surface what was coated with mold release agent. The a layer of peel ply was added on top of the fabric to prevent sticking to the mold and two layers of infusion mesh were placed on peel ply at the top and bottom of the mold to facilitate the resin flow. A vacuum bag was created and sealed with gum tape around the entire package. An external hose was connected to the inlet of the resin tank and another to the vacuum pump for pumping. Before the resin was introduced, the trapped air inside the mold was removed by turning the pump on. Excess resin was removed through the vent line and led to the catch pot, also shown in Figure 2. Finally, the inlet was closed and the vent remained open during the curing process. When the resin was cured completely (about $24 \mathrm{~h}$ later), the CFRP laminate was removed from the mold.

\subsection{Test specimens}

The testing coupons were cut to dimensions of $80 \times 12.7 \times t$ where $t$ is the thickness according to the ASTM D790 for static flexural, fatigue and impact

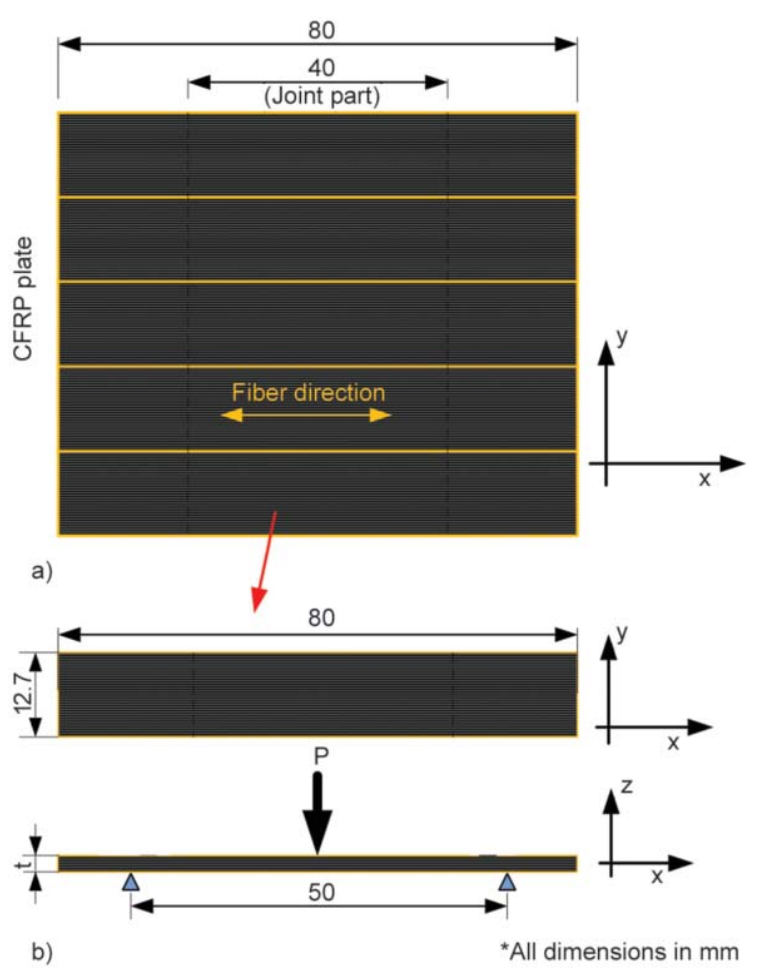

Figure 3. Specimen preparation procedure: (a) The location of specimens taken from CFRP plate and (b) an illustration of the specimen for the three-point bending test.

testing. The average thickness of the samples for each joint type is given in Table 2. Five different types of composites, four types of joints and a jointless composite (test series) were tested with five specimens were tested for each series.

Table 2. Measured thickness, density and void content.

\begin{tabular}{|l|c|c|c|c|c|}
\hline \multicolumn{1}{|c|}{ Adhesive joint } & $\begin{array}{c}\boldsymbol{\rho}_{\text {theoretical }} \\
{\left[\mathbf{g} / \mathbf{c m}^{3}\right]}\end{array}$ & $\begin{array}{c}\boldsymbol{\rho}_{\text {exp,wd }} \\
{\left[\mathbf{g} / \mathbf{c m}^{3}\right]}\end{array}$ & $\begin{array}{c}\text { Fiber } \\
\text { (by acid digestion) } \\
{[\mathbf{w t} \mathbf{m}]}\end{array}$ & $\begin{array}{c}\boldsymbol{\rho}_{\text {exp,ad }} \\
{[\mathbf{w t} \mathbf{\%}]}\end{array}$ & $\begin{array}{c}\text { Void content } \\
{[\mathbf{\%}]}\end{array}$ \\
\hline Jointless & 1.55 & $1.58 \pm 0.08$ & $0.72 \pm 0.04$ & $1.54 \pm 0.04$ & 2 \\
\hline Laminated joint & 1.55 & $1.57 \pm 0.08$ & $0.70 \pm 0.02$ & $1.53 \pm 0.02$ & 2 \\
\hline Laminated joint with 20 mm overlap & 1.55 & $1.56 \pm 0.05$ & $0.72 \pm 0.05$ & $1.54 \pm 0.05$ & 1 \\
\hline Laminated joint with 40 mm overlap & 1.55 & $1.55 \pm 0.04$ & $0.71 \pm 0.01$ & $1.53 \pm 0.01$ & 1 \\
\hline Multiple-covers laminated joint & 1.55 & $1.55 \pm 0.05$ & $0.73 \pm 0.03$ & $1.55 \pm 0.03$ & 0 \\
\hline
\end{tabular}

$\rho_{\text {theoretical }}$ : Theoretical density

$\rho_{\text {exp,wd: }}$ : Measured density from water displacement method

$\rho_{\text {exp,ad}}$ : Measured density from acid digestion method 


\subsection{Characterization techniques}

\subsubsection{Microscopy}

A Leica DM2500 polarized light optical microscope was used to study the modes of damage and crack propagations with respect to the type of joint in posttest impact samples.

\subsubsection{Specific density and void content}

The water displacement method was used to measure the specific density according to ASTM D792. The void content of the composites was measured using acid digestion test according to ASTM D3171. Nitric acid $70 \%$ was used to dissolve the epoxy matrix of the composites at $80^{\circ} \mathrm{C}$ for $24 \mathrm{~h}$. Then, the remaining carbon fibers were thoroughly washed with distilled water, dried at $50^{\circ} \mathrm{C}$ for $2 \mathrm{~h}$ and weighed to determine the fiber mass fraction and void content. The void content for composites is calculated according Equation (1):

$V_{\text {void }}=100 \cdot \frac{\rho_{\text {exp }, \mathrm{wd}}-\rho_{\text {exp }, \mathrm{ad}}}{\rho_{\text {exp }, \mathrm{wp}}}$

where $\rho_{\text {exp,wd }}$ and $\rho_{\text {exp,ad }}$ are the measured density from water displacement and acid digestion method respectively. $\rho_{\text {exp,ad }}$ is determined by substituting the measured fiber mass fraction and the known densities of the fiber and matrix in Equation (2), i.e. the density of the composite:

$\rho_{\text {theoreticd }}=\frac{1}{\frac{w_{\mathrm{f}}}{\rho_{\mathrm{f}}}+\frac{w_{\mathrm{m}}}{\rho_{\mathrm{m}}}}$

where $w_{\mathrm{f}}$ and $w_{\mathrm{m}}$ are mass fraction, and $\rho_{\mathrm{f}}$ and $\rho_{\mathrm{m}}$ are density of the fibers and resin, respectively. For each joint type, five samples were tested.

\subsubsection{Mechanical testing}

Three point bending test according to ASTM D79002 was used to determine the flexural properties. An an Instron 33R 4466 with $10 \mathrm{kN}$ load cell was used. The displacement rate was $1 \mathrm{~mm} / \mathrm{min}$. Each data point is an average of five tests. The modulus was calculated as the slope between the axial strain values of 0.05 and $0.2 \%$.

The fatigue life of adhesive joints was determined using fatigue three-point bending tests with the tests using a $50 \mathrm{kN}$ servo hydraulic Instron 661-21A-02, according to the general recommendations of ASTM D790-02. Fatigue tests were conducted under load controlled sinusoidal loading at a frequency of $5 \mathrm{~Hz}$ in ambient temperature. The load ratio (or stress ratio as the sample thickness and width are cancelled out), i.e. $S_{\mathrm{R}}=S_{\min } / S_{\max }$, was 0.1 and the maximum stress $\left(S_{\max }\right)$ for each type of adhesive joint was selected to be $60 \%$ of the average flexural strength of that joint obtained from the static flexural tests.

Charpy with non-notched specimens with a $43 \mathrm{~mm}$ support span using an Instron SI series pendulum impact tester was used to determine the impact strength. A maximum impact head of $406.7 \mathrm{~J}$ according to ISO179 was used. Each data point presented is an average of five tests.

\section{Results and discussion}

\subsection{Specific density and void content}

The density and void content as determined experimentally for all four types of joints investigated are presented in Table 2. The theoretical density is calculated using Equation (2) and based on $72 \mathrm{wt} \%$ carbon fibers used in manufacturing of the different types of joints according to the acid digestion studies. The void contents are calculated based on Equation (1). The average measured densities of all composite joints are in a same range considering the statistical error. The void content in different types of adhesive joints ranges from 0 to $2 \%$. Considering that similar fiber content and void content assure that manufacturing of different joint types is consistent, any difference observed in mechanical and fatigue properties can be directly attributed to the joint type and not structural defects introduced during the manufacturing process. However, it is noted that if one focuses on the individual measurements and not the average values then there is a big deviation in case of density values and void content values measured in case of the joints with $20 \mathrm{~mm}$ overlap length. The problems is that the testing coupons were not labelled properly so we do not have the value of density and the corresponding void content for a given testing coupon. Our hypothesis, that the large standard deviation in the fatigue results in case of joints with $20 \mathrm{~mm}$ overlap length is supported by literature [26] where is reported that there is a strong correlation between fatigue strength and void content in CF composites made by VARTM.

\subsection{Mechanical properties}

Figures 4 and 5 present how the joint type affects the flexural and impact behaviour of the composites. In it noted that the values of strength and modulus reported are normalized with respect to the thickest 

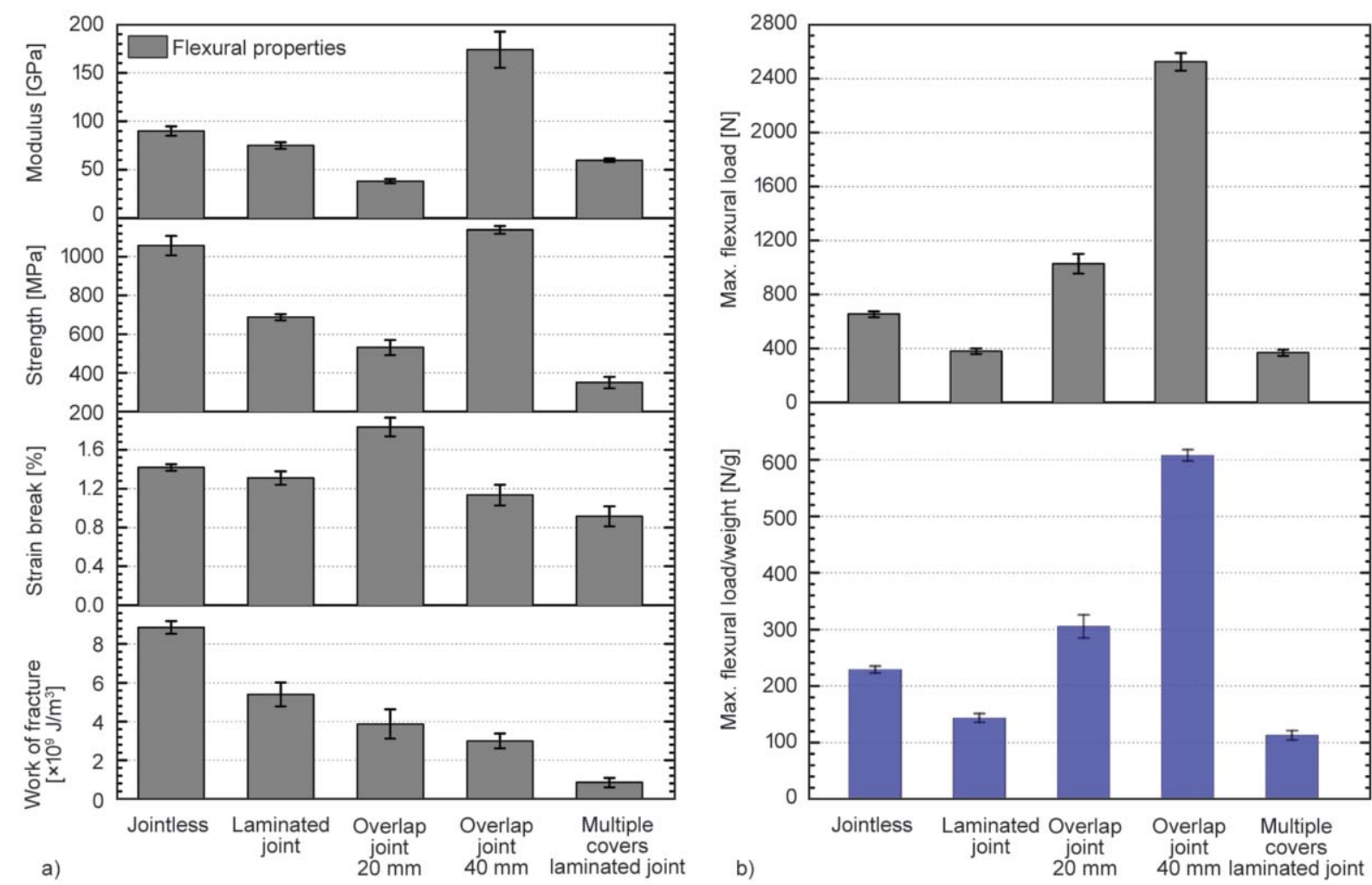

Figure 4. (a) Flexural properties of the adhesive joints (properties measured based on the thickest cross section) and (b) maximum flexural load (absolute and normalized with respect to the joint weight). Error bars are 1 standard deviation.

cross section area whereas the impact results and maximum load are normalized with respect to the weight of the joint. We chose thick cross section over thin cross section in the calculation of the flexural modulus and strength to yield more conservative values for each type of joint. As expected the laminated joint, where the two composite pieces are glued together with no overlap of the $\mathrm{CF}$ fabric, exhibits lower flexural modulus and strength compared to the jointless CFRP. Introducing a $20 \mathrm{~mm}$ overlap of the CF fabric resulted in a joint that was even weaker both in terms of modulus and strength which is counterintuitive. The results indicate that either the overlap was not long enough to enable sufficient load transfer across the fabrics and/or the out-of-plane bending of the fabrics (necessary in order to have the overlap) compromises the ability of the fabrics to withstand flexural load. Once the overlap length increased from 20 to $40 \mathrm{~mm}$, the flexural modulus and strength increased by a factor of two and by more than $20 \%$ respectively, compared to the corresponding properties of the jointless composite. Apparently, the $40 \mathrm{~mm}$ overlap length of the CF fabrics facilitated the load transfer across the fabrics and made the composite stiffer and stronger. It is noted that the $40 \mathrm{~mm}$ overlap join made the composite less ductile, where the

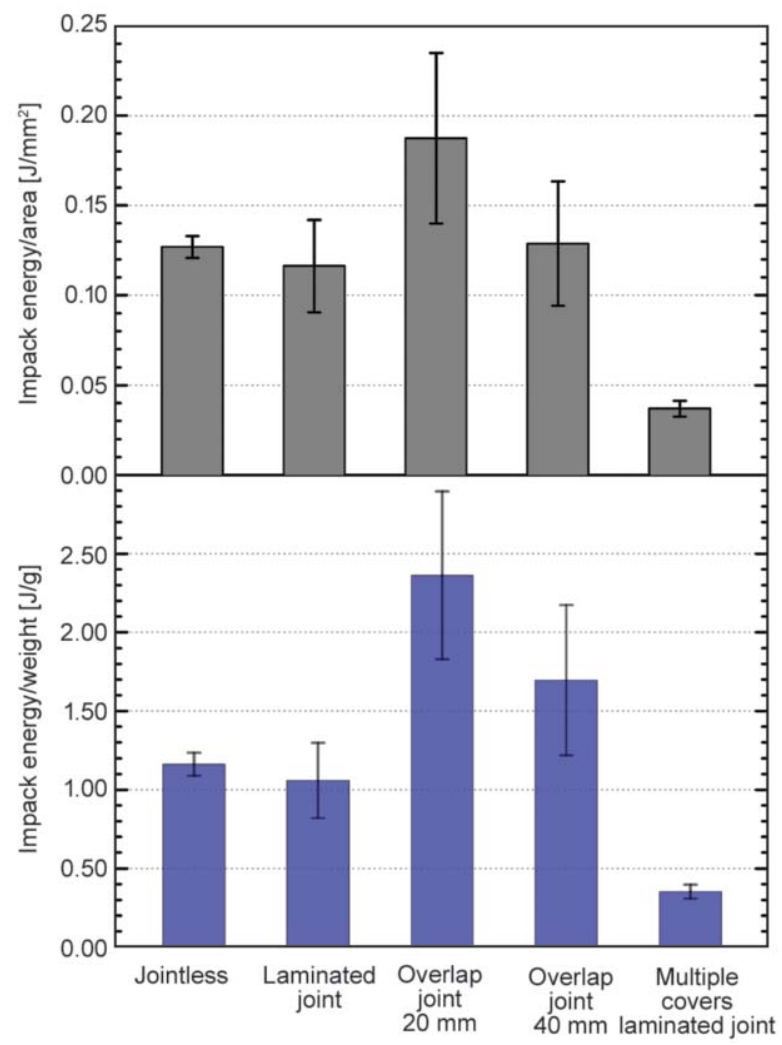

Figure 5. Impact properties of the adhesive joints. Area is the cross-sectional area measured at the thickest part of the sample. Error bars are 1 standard deviation. 
elongation at break was reduced and less tough as it exhibited the lowest work of fracture compared to all other composites tested.

It is noted that the composites with joints with 20 and $40 \mathrm{~mm}$ overlap exhibited higher impact strength compared to the other types of joints and to the jointless composite used for baseline comparison, as presented in Figure 5. A possible explanation for this behaviour, as discussed also below, is the presence of various damage modes, in case of the joints with overlap, including delamination and transverse cracking which provide mechanisms for energy absorption during impact. In contrast, the impact strength was the lowest in case of joints with multiple covers due to weak bonding between the mating dents of the joint.

\subsection{Fatigue tests}

The maximum applied stress for fatigue tests was determined based on the $60 \%$ of the average of the maximum static flexural stress of adhesive joints plotted in Figure 4b. Maximum and minimum applied stresses in fatigue testing are presented in Table 3 for the various types of adhesive joints.

A comparison of the fatigue life of single specimens of different types of adhesive joints is presented in Figure 6 whereas a comparison of the fatigue life of adhesive joints with respect to the maximum applied stress used in fatigue testing is presented in Figure 7. The data of every single sample, instead of average values, has been reported to provide a better comparison for different types of adhesive joints. It is noted that the jointless samples never broke under fatigue loading and the fatigue tests for these types of samples were manually stopped. Laminated joints with $20 \mathrm{~mm}$ overlap and laminated joints with multiple covers show the highest average fatigue lives compared to the other types of joints, as shown in Figure 6. Moreover, the applied stress during the fatigue testing on the laminated joints with $20 \mathrm{~mm}$ overlap is higher than that of laminated joints with multiples

Table 3. Maximum and minimum applied load in fatigue testing for various types of adhesive joints.

\begin{tabular}{|l|c|c|}
\hline \multicolumn{1}{|c|}{ Adhesive joint } & $\begin{array}{c}\boldsymbol{S}_{\max } \\
{[\mathbf{N}]}\end{array}$ & $\begin{array}{c}\boldsymbol{S}_{\min } \\
{[\mathbf{N}]}\end{array}$ \\
\hline Jointless & 400 & 40 \\
\hline Laminated joint & 230 & 23 \\
\hline Laminated joint with $20 \mathrm{~mm}$ overlap & 617 & 62 \\
\hline Laminated joint with 40 mm overlap & 1516 & 152 \\
\hline Multiple-covers laminated joint & 221 & 22 \\
\hline
\end{tabular}

Frequency: $5 \mathrm{~Hz}$

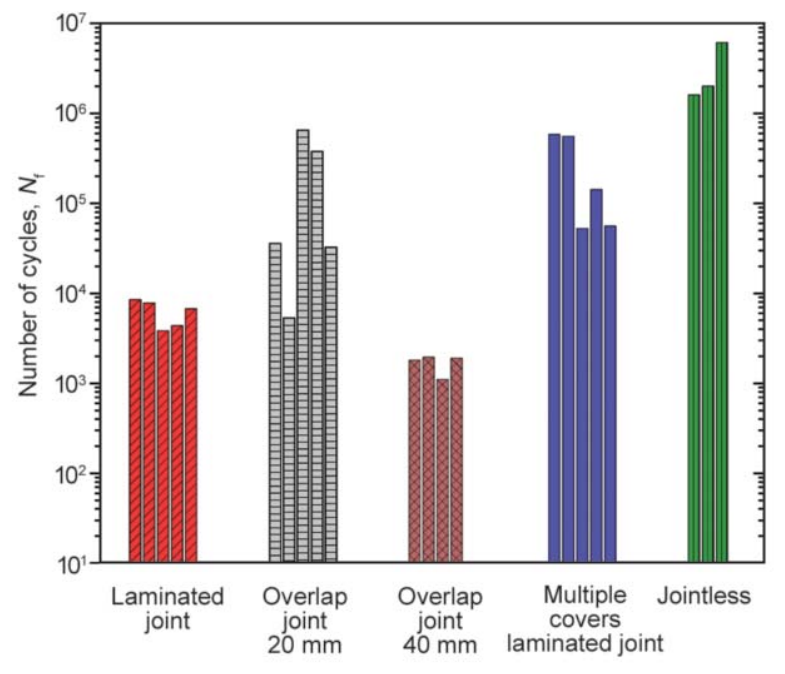

Figure 6. The fatigue life of single specimen of different types of adhesive.

covers [MPa], implying a higher endurance of these types of joints among the others, as shown in Figure 7. It is noted that the stresses are calculated using the measured maximum load and the thick cross sectional area of the samples.

The damage surface analysis indicates that laminated joints with $20 \mathrm{~mm}$ overlap length exhibit various modes of failure such as delamination, transverse cracking and fiber breakage, compared to laminated joints with multiple covers, in which the separation of mating dents is the dominant damage mode which indicates that mating dents are not strongly adhered to each other. The superiority of the joints with $20 \mathrm{~mm}$ overlap length in terms of fatigue behavior, i.e. a larger number of cycles before failure, can be deduced from the higher maximum flexural stresses compared to those of the multiple cover joints, as shown in Figure 7.

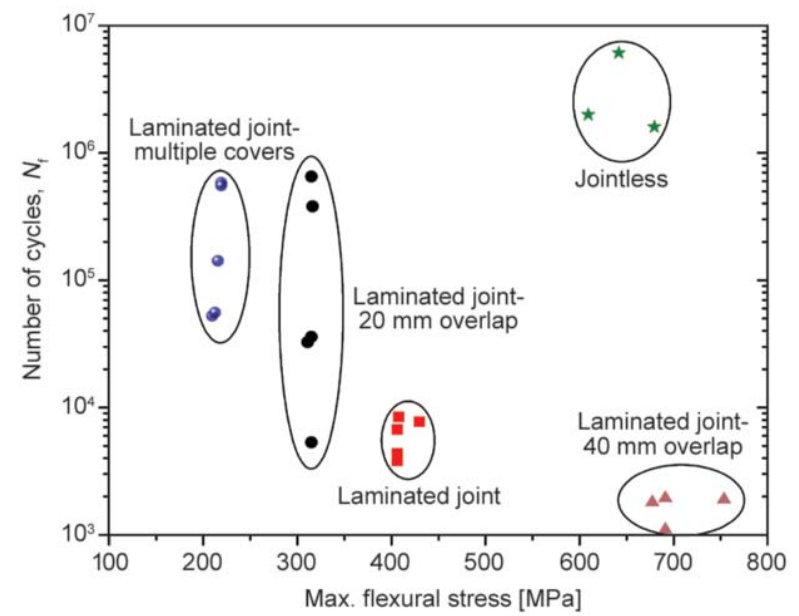

Figure 7. The fatigue life of single specimen of different types of adhesive joints as a function of the maximum applied stress. 

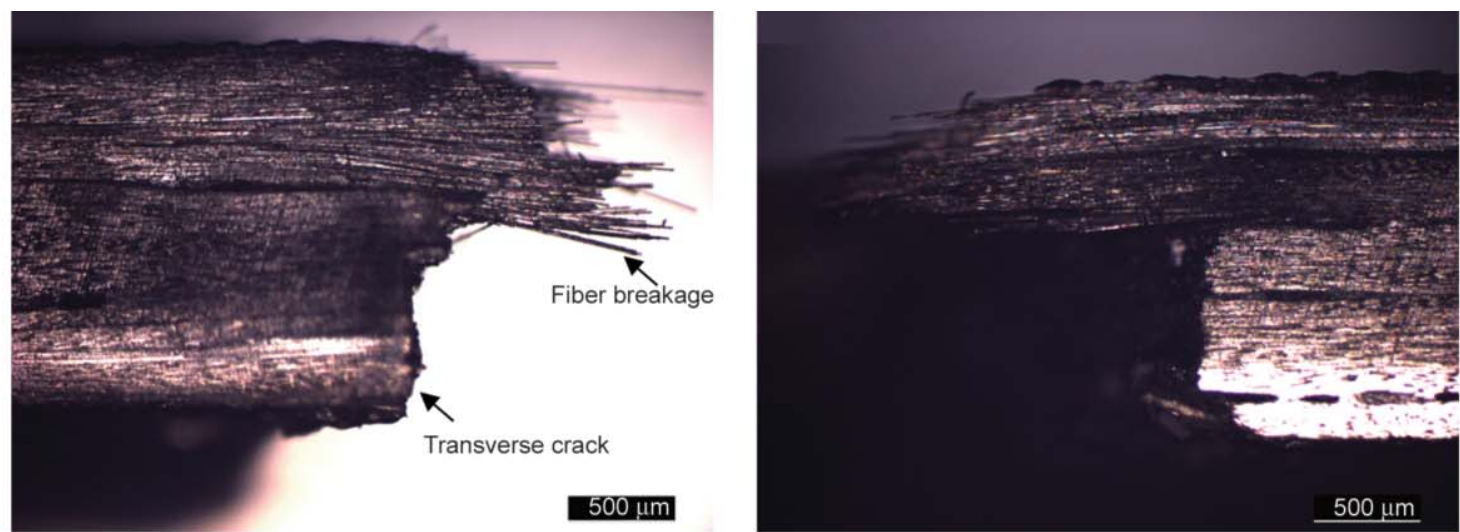

a)

b)
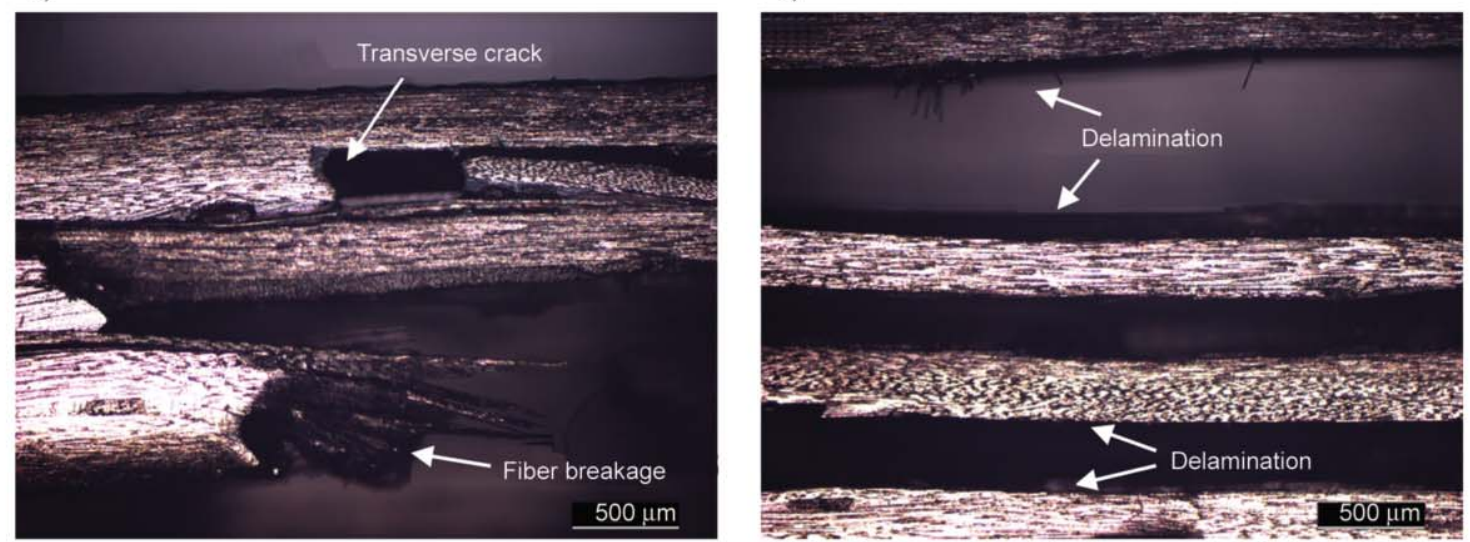

c) d)
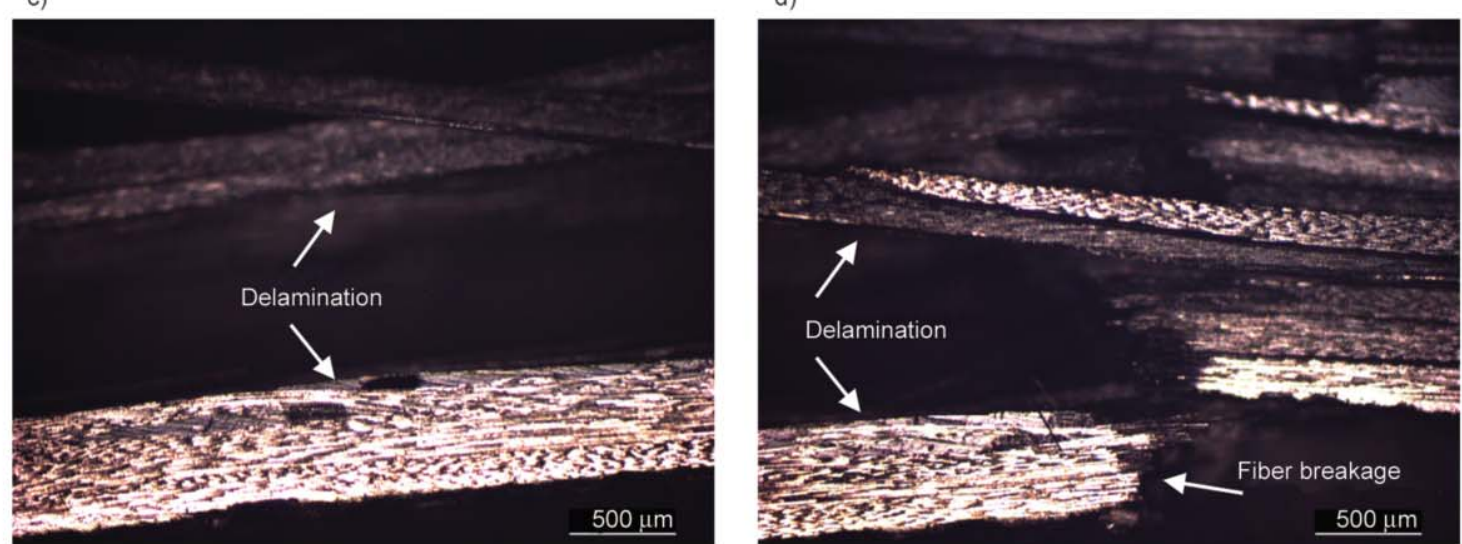

e)

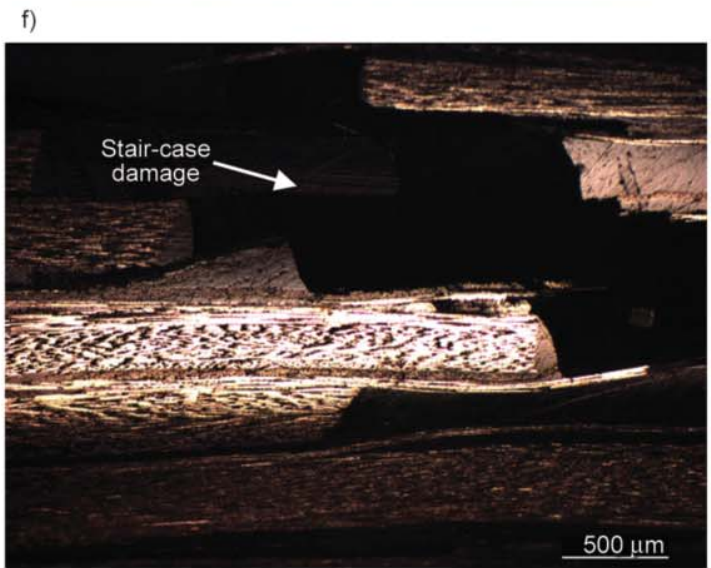

h)

Figure 8. damage modes in different types of adhesive joints; (a) and (b) jointless; (c) and (d) laminated joint; (e) and (f) laminated joint with $20 \mathrm{~mm}$ overlap; (g) laminated joint with $40 \mathrm{~mm}$ overlap; (h) multiple-covers laminated joint. 


\subsection{Failure modes in impact}

We qualitatively investigated the damage/failure modes using optical microscopy to understand the variation of impact strength in different types of joints. The main failure modes in the post-mortem impact samples are delamination between the plies and fiber breakage as shown in Figure 8. In addition, transverse cracking (matrix cracking) as one mode of damage which starts at early stages of loading and continue until the final stages close to catastrophic failure is observed in all types of joints. Although transverse cracking usually does not result in catastrophic failure in multidirectional laminates by itself, other failure modes such as delamination can be triggered from transverse crack location [27]. Delamination usually develop in the final stages of loading prior to catastrophic failure [28]. In contrast to the jointless laminates in which fiber breakage is the leading failure mode, other damage/failure modes as transverse cracking, delamination and separation of the mating stair-step indentations develop in addition to fiber breakage in adhesive joint composites (especially the laminated joint with overlap) leading to higher resistance to impact. It is noted that separation of the mating stair-step indentations possibly triggered by transverse cracking is dominant to other failure modes in multiple-covers laminated joints (Figure 8h).

\section{Conclusions}

In order to investigate the effect of joint type on the mechanical behavior of carbon fiber/epoxy composites four different types of joints were fabricated using the VARTM process and tested. There four types are i) laminated joint, ii) laminated joint with $20 \mathrm{~mm}$ overlap, iii) laminated joint with $40 \mathrm{~mm}$ overlap; and iv) multiple-covers laminated joint. The joints were compared to each other in terms of void content, flexural properties, impact strength and fatigue life. The fiber and void content of all samples were similar. In static flexural and impact testing, laminated joints with with 20 and 40 mm overlap exhibited the best performance whereas the multiple covers laminated joints resulted in the weakest performance. In fatigue life, the laminated joints with $20 \mathrm{~mm}$ overlap and multiple covers showed better fatigue life compared to the other types of joints. Despite the similar fatigue life, the maximum applied stress in fatigue testing of joints with $20 \mathrm{~mm}$ overlap was higher than that of joints with multiple covers suggesting a better endurance for joints with $20 \mathrm{~mm}$ overlap. The microstructure of the fracture surfaces resulted from impact testing, studied using optical microscopy, revealed that the both joint types with overlap i.e., the joints with 20 and $40 \mathrm{~mm}$ overlap showed more extensive transverse cracking as well as delamination, an indication of better impact properties, compared to jointless laminates. In addition, fracture surface analysis showed that the dominant failure mode in laminated joints with multiple covers were separation of mating stair-step indentations compared to delamination and fiber breakage in joints with $20 \mathrm{~mm}$ overlap, potentially leading to better fatigue endurance in joints with $20 \mathrm{~mm}$ overlap.

\section{Acknowledgements}

This work was partly supported by a research grant from the Japan Society for Promotion of Science (\#JP26630496) and by the Collaborative Research Program of Research Institute for Applied Mechanics, Kyushu University. The authors would like to thank Matthew Roth for preparing the figures. The base of this work was presented in Abusrea M., Asadi A., Arakawa K., Colton J., Kalaitzidou K.: Improvements of CFRP composite laminated joint fabricated from two dry carbon halves using vacuum assisted resin transfer moulding VARTM. in ' 21 st International Conference on Composite Materials. Xi'an, China' p.9 (2017).

\section{References}

[1] Keller T., Vallée T.: Adhesively bonded lap joints from pultruded GFRP profiles. Part I: Stress-strain analysis and failure modes. Composites Part B: Engineering, 36, 331-340 (2005).

https://doi.org/10.1016/j.compositesb.2004.11.001

[2] Araújo H. A. M., Machado J. J. M., Marques E. A. S., da Silva L. F. M.: Dynamic behaviour of composite adhesive joints for the automotive industry. Composite Structures, 171, 549-561 (2017).

https://doi.org/10.1016/j.compstruct.2017.03.071

[3] Bakis C. E., Bank L. C., Brown V. L., Cosenza E., Davalos J. F., Lesko J. J., Machida A., Rizkalla S. H., Triantafillou T. C.: Fiber-reinforced polymer composites for construction-State-of-the-art review. Journal of Composites for Construction, 6, 73-87 (2002).

https://doi.org/10.1061/(ASCE)1090-0268(2002)6:2(73)

[4] Pendhari S. S., Kant T., Desai Y. M.: Application of polymer composites in civil construction: A general review. Composite Structures, 84, 114-124 (2008). https://doi.org/10.1016/j.compstruct.2007.06.007

[5] Mouritz A. P., Gellert E., Burchill P., Challis K.: Review of advanced composite structures for naval ships and submarines. Composite Structures, 53, 21-42 (2001). https://doi.org/10.1016/S0263-8223(00)00175-6 
[6] Soutis C.: Polymer composites in the aerospace industry. Elsevier, Amsterdam (2015).

[7] Thoppul S. D., Finegan J., Gibson R. F.: Mechanics of mechanically fastened joints in polymer-matrix composite structures - A review. Composites Science and Technology, 69, 301-329 (2009).

https://doi.org/10.1016/j.compscitech.2008.09.037

[8] Friedrich C., Hubbertz H.: Friction behavior and preload relaxation of fastening systems with composite structures. Composite Structures, 110, 335-341 (2014). https://doi.org/10.1016/j.compstruct.2013.11.024

[9] Huang Y., Meng X., Xie Y., Wan L., Lv Z., Cao J., Feng $\mathrm{J} .:$ Friction stir welding/processing of polymers and polymer matrix composites. Composites Part A: Applied Science and Manufacturing, 105, 235-257 (2018). https://doi.org/10.1016/j.compositesa.2017.12.005

[10] Shin K. C., Lim J. O., Lee J. J.: The manufacturing process of co-cured single and double lap joints and evaluation of the load-bearing capacities of $\mathrm{co}$-cured joints. Journal of Materials Processing Technology, 138, 89-96 (2003). https://doi.org/10.1016/S0924-0136(03)00054-2

[11] Oplinger D. W.: Mechanical fastening and adhesive bonding. in 'Handbook of composites' (ed.: Peters S. T.) Springer, Boston, 610-666 (1998).

https://doi.org/10.1007/978-1-4615-6389-1 29

[12] Ascione F.: The influence of adhesion defects on the collapse of FRP adhesive joints. Composites Part B: Engineering, 87, 291-298 (2016).

https://doi.org/10.1016/j.compositesb.2015.10.033

[13] Chen D., Arakawa K., Jiang S.: Novel joints developed from partially un-moulded carbon-fibre-reinforced laminates. Journal of Composite Materials, 49, 1777-1786 (2015). https://doi.org/10.1177/0021998314540195

[14] Quaresimin M., Ricotta M.: Fatigue behaviour and damage evolution of single lap bonded joints in composite material. Composites Science and Technology, 66, 176-187 (2006). https://doi.org/10.1016/j.compscitech.2005.04.026

[15] Abusrea M., Jiang S., Chen D., Arakawa K.: Novel CFRP adhesive joints and structures for offshore application. in ' $17^{\text {th }}$ International Conference on Material Science and Material Engineering, Istanbul, Turkey' Vol 9, 1176-1179 (2015).

[16] Rahman N. M., Sun C. T.: Strength calculation of composite single lap joints with fiber-tear-failure. Composites Part B: Engineering, 62, 249-255 (2014). https://doi.org/10.1016/j.compositesb.2014.03.004

[17] de Castro J., Keller T.: Ductile double-lap joints from brittle GFRP laminates and ductile adhesives, Part I: Experimental investigation. Composites Part B: Engineering, 39, 271-281 (2008).

https://doi.org/10.1016/j.compositesb.2007.02.015
[18] Heim D., Hartmann M., Neumayer J., Klotz C., AhmetTsaous Ö., Zaremba S., Drechsler K.: Novel method for determination of critical fiber length in short fiber carbon/carbon composites by double lap joint. Composites Part B: Engineering, 54, 365-370 (2013).

https://doi.org/10.1016/j.compositesb.2013.05.026

[19] Hart-Smith L. J.: Further developments in the design and analysis of adhesive-bonded structural joints. ASTM International, West Conshohocken (1981). https://doi.org/10.1520/STP33472S

[20] Akpinar S.: The strength of the adhesively bonded steplap joints for different step numbers. Composites Part B: Engineering, 67, 170-178 (2014). https://doi.org/10.1016/j.compositesb.2014.06.023

[21] Li J., Yan Y., Zhang T., Liang Z.: Experimental study of adhesively bonded CFRP joints subjected to tensile loads. International Journal of Adhesion and Adhesives, 57, 95-104 (2015). https://doi.org/10.1016/j.ijadhadh.2014.11.001

[22] Khashaba U. A., Aljinaidi A. A., Hamed M. A.: Fatigue and reliability analysis of nano-modified scarf adhesive joints in carbon fiber composites. Composites Part B: Engineering, 120, 103-117 (2017). https://doi.org/10.1016/j.compositesb.2017.04.001

[23] Gunnion A. J., Herszberg I.: Parametric study of scarf joints in composite structures. Composite Structures, 75, 364-376 (2006). https://doi.org/10.1016/j.compstruct.2006.04.053

[24] Neto J. A. B. P., Campilho R. D. S. G., da Silva L. F. M.: Parametric study of adhesive joints with composites. International Journal of Adhesion and Adhesives, 37, 96-101 (2012). https://doi.org/10.1016/j.jijadhadh.2012.01.019

[25] Abusrea M. R., Arakawa K.: Improvement of an adhesive joint constructed from carbon fiber-reinforced plastic and dry carbon fiber laminates. Composites Part B: Engineering, 97, 368-373 (2016). https://doi.org/10.1016/j.compositesb.2016.05.005

[26] Chambers A. R., Earl J. S., Squires C. A., Suhot M. A.: The effect of voids on the flexural fatigue performance of unidirectional carbon fibre composites developed for wind turbine applications. International Journal of Fatigue, 28, 1389-1398 (2006). https://doi.org/10.1016/j.ijfatigue.2006.02.033

[27] Asadi A., Raghavan J.: Model for evolution of quasistatic transverse cracking in multiple plies of multidirectional polymer composite laminates. Composite Structures, 132, 665-679 (2015). https://doi.org/10.1016/j.compstruct.2015.06.005

[28] Nairn J. A.: Fracture mechanics of composites with residual stresses, imperfect interfaces, and tractionloaded cracks. Composites Science and Technology, 61, 2159-2167 (2001). https://doi.org/10.1016/S0266-3538(01)00110-5 